\title{
"He Does his own and Walks Away" Perceptions About Male Attitudes and Practices Regarding Safe Motherhood in Ekiadolor, Southern Nigeria
}

\author{
${ }^{*}$ O. A. Adeleye and J. Chiwnzie
}

\begin{abstract}
The main study objectives were to highlight male attitudes and practices regarding safe motherhood, and to demonstrate the usefulness of qualitative research methods in studying behaviour-related health problems. The setting was Ekiadolor, a semiurban Nigerian community with an under-resourced district hospital. The study design was a qualitative research, using Focus Group Discussions (FGDs) with females and the local hospital staff as participants, triangulated with Free Listing Interviews (FLIs) and group interviews of males. The FGD findings showed a consensus that male practices and attitudes were generally unsatisfactory, as exemplified by physical violence against females, delay in enabling access to emergency obstetric care and a general perception that males were uncaring. However, many males paid parts of their partners' routine obstetric care bills. These findings were largely corroborated and enriched by those of the FLIs and group interviews, albeit with differing emphases; they provided vital inputs into health education of the community males. In conclusion, the wide range of attitudes and practices described, and the socioeconomic settings in which they occur, pose challenges and opportunities for behaviour change interventions primarily targeting males, poverty reduction and health service reforms. Health researchers are challenged to draw from the varied strengths of qualitative research methods. (Rev Afr Santé Reprod 2007; 11[1]:76-89)
\end{abstract}

\section{RÉSUMÉ}

"IL FAIT LE SIEN ET IL S'EN VA". Perceptions à l'égard des attitudes et des pratiques des hommes concernant la maternité sans danger à Ekiadolor, au sud du Nigéria Les objectifs principaux de l'étude étaient de mettre l'accent sur les attitudes et les pratiques des hommes concernant la maternité sans danger et de démontrer les bénéfices des méthodes de la recherche qualitative dans l'étude des problèmes de santé liés au comportement. Le cadre était Ekiadolor, une communauté semi-urbaine nigériane qui dispose d'un hôpital régional qui ne dispose pas de ressources nécessaires. La conception de l'étude était une recherche qualitative, à l'aide des Discussions à Groupe Cible (DGC) ayant les femmes et le personnel local de l'hôpital comme participants, triangulé avec les interviews libres (IL) et les interviews en groupe pour les hommes. Les résultats du DGC ont montré un consensus sur le fait que les pratiques et les attitudes des hommes étaient dans l'ensemble peu satisfaisantes, comme elles ont été manifestées par la violence physique contre les femmes, le retard par rapport à l'accès aux soins obstétriques d'urgence et une perception générale que les hommes sont insensibles. Néanmoins, beaucoup d'hommes ont payé une partie des facteurs de routine de leurs partenaires pour les soins obstétriques. Ces résultats ont été largement corroborés et enrichis par ceux des ILs et des interviews en groupes, quoique avec des accents différents; ils ont donné des apports importants à l'éducation de la santé des hommes dans la société. En conclusion, les grandes varieties d'attitudes et des pratiques décrites et les cadres socio-économiques dans lesquels elles se présentment, posent des défis et des opportunités pour des intervention dans les modifications dans le comportement qui visent essentiellement les cibles masculins, la réduction de la pauvreté et les réformes des services de santé. Les chercheurs dans le domaine de la santé sont défiés de profiter des divers points forts des méthodes de la recherche qualititative. (Rev Afr Santé Reprod 2007; 11[1]:76-89)

KEY WorDS: Safe motherhood; male attitudes and practices; Focus Group Discussion; Free Listing Interview; Nigeria.

Department of Community Health, School of Medicine, University of Benin, Benin City, Nigeria.

*Corresponding author: Dr. Omokhoa A. Adeleyedoctoradeleye@yahoo.com 


\section{Introduction}

Maternal health in developing countries, including Nigeria, is in a deplorable state. In 2000 , maternal mortality ratio was 400 per 100,000 live births world-wide, 440 per 100,000 live births in developing countries and 800 per 100,000 live births in Nigeria. ${ }^{1}$

Against this background, male involvement in safe motherhood is evolving as an important approach to intervention. This is partly because males play essential roles in the reproductive experiences of females and partly because they are often culturally placed as decision-makers. However, patriarchy, ignorance and poverty may make it easy for males to take wrong decisions or no decision on matters relating to the health of their female partners, even when an obvious need for urgent and appropriate decision exists. This is in the face of a campaign that calls for increased maternal decision-making power as a right, while paying little regard to the need for informed paternal support.

Literature on male involvement in reproductive health from many countries, including Nigeria, suggest that a significant proportion of men have negative attitudes towards family planning, largely due to their ignorance and dominance, and the absence of adequate inter-partner communication on the subject. ${ }^{2,3}$ Male dominance was also demonstrated in another Nigerian study that showed that the husband alone took the decision on the choice of the health facility to be used by his wife for antenatal care. ${ }^{4} \mathrm{~A}$ study in the Philippines shows that wife battering occurs in an atmosphere where the wife fears the husband. ${ }^{5}$ In spite of this situation, it has been shown that men's attitudes and practices can be improved upon. For example, in an intervention to prevent maternal mortality in a Nigerian community, men were successfully mobilised to urgently transport women with obstetric complications to appropriate health facilities. ${ }^{6}$

African Journal of Reproductive Health Vol. 11 No.1 April, 2007
These observations highlight the need to further study male attitudes and practices regarding safe motherhood, using approaches that enable clearer insight into the nature of the phenomenon.

The main objective of this study is to contribute to efforts geared towards enhancing safe motherhood by qualitatively determining perceptions of females and health care workers about male attitudes and practices as a basis for corrective interventions. The second is to demonstrate the usefulness of qualitative research methods in providing data for the reinforcement of surveys and intervention tools that deal with attitude- and behaviour-related health problems. It is hoped that researchers in health-related fields who need to go beyond the use of quantitative designs alone to study such problems will, through this study, understand the methods and usefulness of qualitative studies.

\section{METHODOLOGY STUDY PLACE}

The study was conducted in Ekiadolor, a semiurban community in Ovia North-East Local Government Area, Edo State, Southern Nigeria. The Prevention of Maternal Mortality Network posits that only after nearby facilities are able to provide emergency obstetric care does it make sense to address community-based barriers. ${ }^{7}$ Following this criterion, Ekiadolor was randomly selected from the eight communities within a 20minute drive from a tertiary health care facility the University of Benin Teaching Hospital (UBTH), Benin City.

Official estimates put the total population of Ekiadolor at about 3,934 at the time of the study, but its distribution is not officially accessible. Empirical evidence, however, indicates that the distribution roughly approximates state and national averages. Edo State population distribution shows that females in the reproductive 
age group of 15-49 years are about $22.8 \%$ of the population. ${ }^{18}$ As similarly depicted in the national population, younger persons in the study population have a higher level of formal education than the older ones. Thus, among the females, median years of schooling is 5.8 in the age group 15-24 years and 0.0 for 35 years and above; among the males, this variable is about 8.0 in the age group 15-24 years, 6.2 for 35-39 years and 0.0 for 55 years and above. ${ }^{19}$ It is therefore not surprising that more than $90 \%$ of the married females resident in the community are not literate, having had little or no formal education. In contrast, most of the single females in the reproductive age group, being younger, have completed primary and attempted junior secondary education. Many are unemployed, and the working population largely consists of peasant farmers and petty traders. A crude estimate of income per capita in the community is about $\$ 1.00$ per day. The predominant ethnic group is Bini which constitute about $70 \%$ of the population; others include Igbo, Urhobo, Esan, Etsako, Ijaw, Isoko and Yoruba.

The community is traditionally patriarchal. For example, while two major community groups youths and elders - exist, females are merely allowed in the former and invariably excluded from the latter.

A state-government-owned district hospital is the only health care facility providing maternal health services in the community. It is manned by 3 nursing officers/midwives and, occasionally, a pharmacist and a medical doctor. These staffs, however, do not reside in the community and they usually offer daytime services with occasional skeletal night services by a nurse/midwife. The major maternal health services rendered by the hospital are family planning, antenatal care, normal (spontaneous) delivery and patient referral. Occasionally, when there is a doctor, evacuation of retained products of conception, blood transfusion and treatments of sepsis and pregnancy-induced hypertension are carried out.
Instrumental deliveries, including Caesarean sections, are not done as the hospital is ill-equipped for these; in particular, the operating theatre is non-functional. Public electricity and water supplies to the community and hospital are very erratic and the hospital has no alternative sources; these further compromise the services. The laboratory supports for the hospital services are in Benin City. Data on service utilisation and outcomes are poorly kept; mortality data are virtually absent. However, unofficial information from staff and community members indicate that utilisation rates are very low. About 3 deliveries per month are taken, implying a crude birth rate of about 9 per annum per thousand population in a country with a crude birth rate of 41.7 per annum per thousand population. ${ }^{19}$ The same unofficial sources also reveal that maternal deaths in the community occur at rates comparable to the national average (see above), especially for patients with complications who are unable to urgently afford or access better facilities in Benin City.

Referrals are usually made to UBTH or Central Hospital in Benin City. These facilities are respectively about 15 -minute drive and 30-minute drive from Ekiadolor, but travelling time could be nearly doubled during hold-ups or when the tarred link-roads are bad; these situations occur mainly at the peak of the rainy seasons. Late night trips are largely ruled out for security reasons. A few untrained traditional birth attendants in the community also take home deliveries on invitation.

Ekiadolor is largely rural but possesses some urban characteristics (such as public electricity, pipe-borne water and tarred roads) in some parts of the community. It may therefore illustrate what exists in many communities in developing countries, including Nigeria.

\section{STUDY DESIGN}

The investigators sought contextual data on experiences, perceptions and expectations of females and health care workers on male attitudes

African Journal of Reproductive Health Vol. 11 No.1 April 2007 
and practices as regards safe motherhood, using focus group discussions (FGDs). ${ }^{8}$ Females were study subjects because they undergo the maternal experience in which males are involved, and are thus able to 'mirror' male attitudes and practices. Health care providers were study subjects because they witness the behaviour and practices of males when they variedly provide (or withhold) support for their female partners receiving medical care, and because they can give information on how males, as family heads in the community, have contributed to (maternal) health services in the district hospital. In addition, the investigators sought inputs into the health education tools intended to correct the identified knowledge, attitude and practice gaps.

A community guide (an elderly and respected male volunteer resident in and conversant with the community, especially its culture) was appointed for the study. His role was to assist the investigators in identifying and reaching community entry points, recruiting and clarifying logistics with participants, group formation, etc. After obtaining the cooperation of the community entry points, the FGD participants were recruited, by purposive selection, into four groups. Participation was entirely voluntary. Four FGD sessions were conducted, one per group. Each group was designed to consist of 4-12 participants. The sessions were held in the cutacross languages preferred by the participants in their respective groups, and this was consistent with their educational statuses and ethnic mix. The characteristics of the focus groups are shown in Table 1.

The principal facilitator in the FGDs was a community health physician with training and field experience in qualitative research, including FGDs and group dynamics. He trained assistants (community development workers with postsecondary education) solely to facilitate in group formation, note-taking and audio cassette recording; their training was conducted in three days - one session of about one hour daily. The principal facilitator conducted the FGD sessions. With the aid of FGD guides, discussion topics were introduced. Opening, topical and probing questions were asked. ${ }^{9}$ Opening questions, as exemplified in the results, were typically "ice breakers" that served as preludes to topical questions; they were used to stimulate interest in the group process, and to elicit the participants' initial perceptions about the general theme. Topical questions directly addressed the topical themes. Probing questions were follow-up questions to obtain more details and clarifications on responses given to topical questions.

The general topical themes for the discussions included: the attitudes, practices and roles of the male partner before, during, and following pregnancy and delivery, including attitudes to family planning; and whether males should be

\section{Table 1. Characteristics of the Focus Groups and Participants}

\begin{tabular}{|c|c|c|c|c|c|c|c|c|}
\hline \multirow{2}{*}{ Focus Groups } & \multirow{2}{*}{$\begin{array}{l}\text { Preferred } \\
\text { Language } \\
\text { for FGD }\end{array}$} & \multicolumn{4}{|c|}{ Educational Status* } & \multicolumn{2}{|c|}{ Ethnic Group } & \multirow{2}{*}{ Tota } \\
\hline & & None & Primary & Secondary & Tertiary & Bini & Others & \\
\hline $\begin{array}{l}\text { 1. Married mothers aged } \\
25 \text { years and above }\end{array}$ & Pidgin English & 4 & 4 & 1 & 0 & 7 & 2 & 9 \\
\hline $\begin{array}{l}\text { 2. Married mothers aged } \\
25 \text { years and above }\end{array}$ & Pidgin English & 4 & 3 & 0 & 0 & 5 & 2 & 7 \\
\hline $\begin{array}{l}\text { 3. Single females aged } \\
18-24 \text { years }\end{array}$ & $\begin{array}{l}\text { English and some } \\
\text { Pidgin English }\end{array}$ & $\begin{array}{l}0 \\
2\end{array}$ & $\begin{array}{l}0 \\
6\end{array}$ & 6 & 0 & 4 & 2 & 6 \\
\hline $\begin{array}{l}\text { 4. District hospital staff } \\
\text { (3 males; } 3 \text { females) }\end{array}$ & English & 0 & 0 & 3 & 3 & 5 & 1 & 6 \\
\hline
\end{tabular}

${ }^{*}$ Highest level attended, whether or not completed

African Journal of Reproductive Health Vol. 11 No.1 April, 2007 
educated on the expressed areas of concern and other aspects of safe motherhood. The hospital staff discussion theme also included how males have contributed, as family heads in the community, to improvement in (maternal) health services in the district hospital. An additional theme for the single females was the male partner's attitude in the event of an unexpected pregnancy.

The sitting arrangement at each session was such that it allowed for easy eye contact and hearing between the principal facilitator and the participants. The participants were encouraged to talk freely and spontaneously. Manual and audio cassette recordings were done. Each session lasted for 30-40 minutes, as allowed by the participants.

A few shifts from the conventional protocol were employed in accordance with local realities. For example, the FGD participants for the female groups preferred to discuss in a group of familiar persons, irrespective of sex or age; they were satisfied with having a male FGD facilitator, since he is a physician (familiar with handling confidential information) and had become familiar with them. Also, the investigators did not provide refreshment during any of the sessions because the local culture disallows guests (as the investigators were regarded) from entertaining hosts.

Within 24 hours after each session, and before the next, the recordings were carefully transcribed and, in the case of the Pidgin English discussions, translated. Peer review mechanisms were used to ensure that the entire handling of the recordings was done without loss or distortion of content and without bias.

The investigators found it necessary to determine, using additional qualitative data, whether the male attitudes and practices perceived to be harmful or beneficial in the FGDs would be similarly acknowledged by the males themselves. The data thus collected would be used to cross-check what had been said by the females and hospital staff in the absence of the males.

Accordingly, Free Listing Interviews (FLIs) ${ }^{9}$ on the beneficial and harmful practices were conducted among males. The respondents were males aged 18 years old and above residing in the community. (They had been selected as respondents by cluster sampling for quantitative data collection as part of the larger database for studies on this subject.) The FLI data were collected by using an interviewer-administered questionnaire containing open-ended multipleresponse questions that requested the individual respondents to itemise the male practices observed in the community to be harmful or beneficial to safe motherhood. The identified items were collated, sorted, scored by their respective frequencies, ranked and presented tabularly.

Furthermore, during each health education session later conducted for males only, group interviews were used to collect contextual qualitative data on their attitudes and practices regarding safe motherhood. The interview was conducted for each of nine groups with a total of 110 consenting married and single males participating in all the quarters of the community. Their tribal mix and educational levels (in terms of school levels attended) were similar to those of the females in the FGDs, but they were, on the average, about 5 years older. The group structure was designed to have no more than 30 participants per group, separate groupings being made for the married as different from the singles. Attendance was higher for the married males than for the singles. Efforts to boost mobilisation of the latter through personal contacts and appeals by their group leaders were minimally successful, a pattern that had been known with male youths in this community regarding meetings. (The major reason adduced for this was that they could not associate such meetings with any immediate economic gain.) The group interview for younger singles was finally conducted at a forum of the youths' meeting which 7 males attended. The topical themes, group management team and logistics were the same as for the FGDs. These interviews were used as baseline 'entry routes' into the health talk presentations and then

African Journal of Reproductive Health Vol. 11 No.1 April 2007 
continued incrementally at appropriate times (when the most closely related health talk lesson is being presented) to obtain more data. The discussion segment that followed each presentation provided opportunities for followup questions on initial responses. The total duration per session was 50-60 minutes (including the duration for the accompanying health talk presentation). This approach offered the advantage of combining knowledge, attitude and practice appraisals and health talks at one sitting, the principles and illustrations of which are available in the literature. ${ }^{20}$

Data from the FGDs, FLIs and group interviews were collected, collated and presented in a manner that permits their overall appreciation as desirable/beneficial as different from the undesirable/harmful attitudes and practices, after which they are then linked up with the design of the content of the health education lessons.

The data are thereafter examined, triangulated and discussed in the light of the objectives. This formed a basis for generating appropriately targeted recommendations. The study limitations are also presented.

\section{Results}

The findings from the FGDs, FLIs and group interviews are presented in sequence. They generally demonstrate consensus, divergence and trends among the participants and respondents.

\section{FINDINGS FROM THE FOCUS GROUP DISCUSSIONS}

The FGD participants were very open from a very early stage of each session. They used the discussions as opportunities to actively express themselves with keen interest on a topic they saw as important to the well-being of females and families.

\section{Desirable Attitudes and Practices}

All the FGD groups were consistent in the view that married males usually gave some support to their wives before, during, and following pregnancy and delivery. Such support included the provision of money for maternal care in modern health facilities and for the care of the baby. Men also helped to take their wives to the hospital and participated in domestic chores and farm work. Married and single males occasionally took responsibility for the reproductive health care of their single sexual partners, especially during pregnancy and delivery. Some men were said to express preference for small family sizes, sometimes against their wives' wishes, although such situations could attract a wife's suspicions that the husband intends to marry another wife, or plans to have children outside wedlock.

The hospital staff FGD revealed that the men in the community took charge of providing security for the hospital and cleaning its environment.

\section{Undesirable Attitudes and Practices}

Perceptions about the undesirable male attitudes and practices were similar in all the groups. In a married mothers' group, in response to an opening question on whether females sometimes wished they were males, a female participant said:

\footnotetext{
"A woman suffers during pregnancy and delivery. On the day of delivery, she has only one leg in life and the other in death. But for the man, he simply does 'bis own' and walks away. He does not know what it takes to deliver a baby."
}

In this statement, the man's role of doing 'his own' refers to sexual intercourse leading to pregnancy.

Undesirable attitudes and practices of males towards their partners, as identified by the FGDs, included engaging in extramarital affairs, which would expose them (the females) to the risk of HIV/AIDS; unwillingness of males to use or allow their wives to use family planning methods; neglecting a wife (including withholding financial help) when she is in labour; subjecting a pregnant wife to burdensome work in order to induce timely labour (that is, to prevent or treat supposed post-datism); and battering a pregnant wife to 
the point that she miscarries. However, the women in one group justified wife beating if a wife was "stubborn" or "bad", but felt that there was no basis for husband beating. Another dimension to female battering was that a third party often executed it in favour of the male partner. A married mother's account illustrates this:

'For insisting, against my husband's wish, on not having more children after having 5, my mother beat me continuously as I ran from that house (pointing to the house) to the end of this road. These people (co-participants) witnessed the event. That was how I was made to have 3 more children. Afterwards, my busband wanted more... So, I've been secretly taking family planning injections... My husband is simply surprised now that I don't get pregnant any more."

Indeed, a situation in which a woman refuses to have more children, or is childless, was locally described as "eating free food without pregnancy", and could lead to divorce.

A participant in the single females' group shared another experience that illustrates the phenomenon of third party assistance in female battering:

"A certain girl became pregnant in the course of relating with her boy friend. The boy neglected her. So, she went to bis family house to seek help from his people. Instead of helping her, both males and females in the house beat her up and pushed her out of the house."

There was consensus among the single females that single males often did not participate in the care of their sexual partners during pregnancy. The group, however, partly blamed this on the fact that males were usually hesitant to believe the pregnancy claims of their sexual partners because some girls lied about it in order to get money from them. In any case, a pregnant girl would procure abortion if his male partner denied responsibility or withheld care.

The women also said that some husbands in the community acted against medical advice with respect to the health of their wives. One woman gave an instance of this:
"A woman in this community was warned by her doctor not to become pregnant without treating a problem in her womb. She nevertheless became pregnant. She delivered her baby at home and then bled uncontrollably from her womb. She was taken to the hospital here, and later to Central Hospital, Benin City where she died on arrival... If her husband had avoided impregnating her, or if he had taken her to hospital for treatment before the pregnancy, the woman would not have died."

Another instance was presented as follows:

"A woman was in labour at home for 2 days before she was taken to our hospital, and thereafter to UBTH where she had a Caesarean section and died shortly afterwards. The child survived but died 3 years later. The problem was that the woman's husband, who was about 70 years old, was too old to care for his wife, and then the surviving children, especially the last child that died."

The discussion also revealed that males have been known to drug their single female partners to sleep in order to procure abortion for them without their consent.

Various other attitudinal and practice problems were described. The hospital staff FGD revealed that men usually took it for granted that a pregnant woman would always deliver safely, except she is a victim of her own witchcraft or that of her enemies, but this belief was not exclusive to men. A married mothers' FGD further revealed that some men blamed their wives for ill-luck if she had a pregnancy complication. A man may send his pregnant wife to live with her mother in order to evade the financial responsibility of care.

\section{Some Cost and Service Considerations}

The discussion revealed that the antenatal booking fee was about $\$ 7.20$ (N1,000.00) per client, and this covers normal (uncomplicated) antenatal care and delivery services. Discussants were satisfied with this fee, but they complained about additional charges (up to \$7.20) put in place by the hospital to purchase and replenish basic supplies and utilities. Caesarean

African Journal of Reproductive Health Vol. 11 No.1 April 2007 
sections in Benin City cost about $\$ 200.00$ to $\$ 300.00$ in the absence of perioperative complications. Some men discouraged their wives from using maternal health services in the local district hospital, except during emergencies. The female groups partly blamed this on the less-than-24-hour-daily coverage of the hospital, the discourteous attitude of the staff and the additional fees charged by the hospital. Indeed, the hospital staff FGD affirmed that it was expensive to deliver in the hospital, but cheaper to deliver at home with the assistance of a traditional birth attendant (about \$4.00). [The authors' cost estimate of reequipping the hospital (infrastructures, medical service equipment, etc) is about \$25,000.00, while monthly running costs would amount to about $\$ 500.00$, apart from salaries. The income per capita estimate of $\$ 1.00$ per day in the community has already been stated.] The hospital, like many other healthcare facilities in the country, does not operate

a periodic budgetary system.

The hospital staff, in their FGD, said that their previous initiatives to mobilise the community (men) to participate in funding and equipping the hospital were unsuccessful. They blamed this on poverty and general public apathy towards government-owned institutions.

\section{FINDINGS FROM THE FREE LISTING INTERVIEWS}

The findings from the FLIs are presented in Tables 2 and 3.
Table 2 shows that encouraging females to use maternal health (including family planning) services, relieving females of overwork especially at home, providing money for the partner's upkeep and showing concern and general care were the most frequently stated beneficial practices. In Table 3, battering, financial neglect (especially during pregnancy), compelling a partner to procure induced abortion and refusal to use or allow the use of a family planning method were the most frequently stated practices.

\section{FINDINGS FROM THE MALE GROUP INTERVIEWS}

\section{Desirable Attitudes and Practices}

Participants were generally open on these, emphasising the sacrifices they sometimes made in the process

- Males in the community owe it as a point of cultural duty to care for their partners

- Since the pregnancy comes from both the males and their partners, they (the males) share in the responsibility of ensuring the wellbeing of the pregnancy all through to child care; they therefore provide money for their partners' maternal healthcare

- They encourage their partners to use modern hospital services as long as they are affordable

Table 2. Practices of Men Believed to Contribute To Safe Motherhood

\begin{tabular}{lrr}
\hline Beneficial Practices & \multicolumn{2}{c}{ Responses } \\
\cline { 2 - 3 } & Frequency & Percent \\
\hline Encouraging females to use maternal health (including family planning) services & 75 & 31.3 \\
Relieving females of overwork especially at home & 53 & 22.1 \\
Providing money for partner's upkeep & 47 & 19.6 \\
Showing concern and general care & 45 & 18.8 \\
Ensuring good nutrition & 11 & 4.6 \\
Giving the hospital material and financial support & 5 & 2.1 \\
Praying for women & 4 & 1.7 \\
\hline Total & 240 & 100.0 \\
\hline
\end{tabular}

$\mathrm{n}($ respondents $)=235,(63.7 \%)$.

African Journal of Reproductive Health Vol. 11 No.1 April, 2007 
84 African Journal of Reproductive Health

Table 3. Practices of Men Believed To Endanger Motherhood

\begin{tabular}{lrr}
\hline Harmful Practices & \multicolumn{2}{c}{ Responses } \\
\cline { 2 - 3 } Battering & Frequency & Percent \\
Financial neglect, especially during pregnancy & 26 & 17.7 \\
Compelling a partner to procure induced abortion & 23 & 15.6 \\
Refusal to use or allow the use of a family planning method & 15 & 10.2 \\
Injurious sexual intercourse & 13 & 8.8 \\
Absence of husband from home & 10 & 6.8 \\
Marital disharmony \& divorce & 9 & 6.1 \\
Extramarital affairs and multiple sexual partners & 8 & 5.4 \\
Rejecting responsibility for pregnancy & 7 & 4.8 \\
Infecting a partner with sexually transmitted infections & 7 & 4.8 \\
Disallowing wife from going to the hospital \& encouraging drug abuse & 6 & 4.1 \\
Sex with, and impregnating underage girls & 5 & 3.4 \\
Overworking the woman & 4 & 2.7 \\
Encouraging contraceptive abuse & 3 & 2.0 \\
Forcing a female partner to use traditional medicine & 2 & 1.4 \\
Withholding sex from female partner & 2 & 1.4 \\
Others & 2 & 1.4 \\
\hline Total & 5 & 3.4 \\
\hline (respondents) & 2 & 100.0 \\
\hline
\end{tabular}

$n($ respondents $)=142,(38.5 \%)$.

- Males no longer seek to bring about more than four children per woman

- Males provide the needed care for their underage daughters who get pregnant

- Men in the community are increasingly playing stronger roles in ensuring the moral upbringing of their children to avoid premarital sex, pregnancy and abortion (reproductive health education)

- Men are willing to do more to resuscitate services in the hospital, especially maternal health services

\section{Undesirable Attitudes and Practices}

Participants were generally unwilling to open up on this, in spite of follow-up questions. The older and married participants stated the first three on this list as desirable.

- Female circumcision is an effective way to curb promiscuity among girls; it will prevent premarital pregnancies and sexually transmitted infections

- A girl is mature enough for marriage as soon as her menses starts

- Men can have as many children as they want as long as the children are not more than four per woman; their fathers will provide for their upkeep as much as he can; their mothers will do the rest

- Untrained and unskilled men carry out induced abortion on girls and women

The FLI findings on harmful practices that they did not mention were fed back to them, and they concurred.

\section{INPUTS INTO THE HEALTH EDUCATION MESSAGES}

Generally, health education lessons were drawn from the FGDs, FLIs and the group interviews that held within the health education sessions by

African Journal of Reproductive Health Vol. 11 No.1 April 2007 
identifying the desirable attitudes and practices for promotion, and the undesirable ones to be discouraged. In addition, the FGDs provided an opportunity for the participants to say what other safe motherhood issues they would want males to be educated about.

The key messages derived from the data and directly suggested by the participants were as follows:

- Men should do more in providing care for their partners before, during and after pregnancy

- Males should relate with their female partners with due regard as fellow human beings

- Female battering should be discouraged and inter-partner communication on reproductive health, especially family planning, should be encouraged

- Men, particularly those who are well-todo, should do more to improve on maternal health services in the local hospital

- The traditional leaders, as custodians of culture, should serve as community change agents in safe motherhood

- Men and women need education on family planning, the need to avoid underage marriages and pregnancies and the danger signs of pregnancy and delivery

Inputs from the FGDs and FLIs were further developed into verbal, non-verbal and pictorial formats, while additional inputs from the group interviews were simultaneously built into the health messages.

\section{Discussion}

A female's expectation of care from her male partner basically exists within a socio-cultural setting. As another Nigerian study shows, both men and women usually accept this arrangement as proper. ${ }^{10}$ This phenomenon provides a basis for expecting a strong role to be played by males in the maternal care of their partners. This is the premise on which this study was designed, conducted and will now be discussed.

The males-only inputs into the study were used to triangulate the data from the FGDs of females and the local district hospital staff. The need arose in order to avoid the bias of a onesided account. The approach thus enables a comparison between what was said about the males on one hand, and what the males said about themselves on the other hand. But a more basic comparison is also enabled - between the data collection methods used for the males-only inputs vis-à-vis the pattern of data collected.

The general pattern of these males-only inputs (both the male group interviews and the FLIs) was that males more frequently provided responses on their desirable/beneficial attitudes and practices than those on the undesirable/ harmful.

In the male group interviews, the participants stated only one practice as undesirable, (three more having been wrongly volunteered as desirable). In contrast, they stated a fair number of key attitudes and practices as desirable. It would therefore appear that the participants were open about their desirable but secretive about their undesirable attitudes and practices.

Tables 2 and 3 measure how often the respective practices were stated by the respondents. The finding of a higher total frequency of responses for beneficial practices suggests that, as similarly shown in the group interviews, males in this study were more willing to volunteer information on their beneficial than on their harmful practices. The lower total frequency for the harmful practices notwith-standing, the range of practices was wider.

The FLIs provided a moderate list of beneficial and harmful practices that enlarged the view got from other methods. This fuller listing is probably traceable to the approach used in this study: the respondents were interviewed 
individually, thus creating better confidentiality than was possible in the group interviews.

It is also remarkable that the group interview participants did not refute the harmful practices which were volunteered in the FLIs. This is not surprising. This indicates that the FLI findings were valid, the data having been collected from the same population segment in the same community at bout the same time. The fact that the FLIs generated more mentions of undesirable/ harmful practices than group interviews suggests that information on negative attitudes and practices are better elicited at individual, rather than group levels.

The FGD data on the perception of females and hospital staff shows that the participants highlighted the undesirable/harmful attitudes and practices of males over and above the desirable/ beneficial. This is in contrast with the pattern of responses from the males themselves in the group interviews, but compares well with the wide range of undesirable/harmful attitudes and practices in the FLIs. It may be concluded, therefore, that the FLIs of males and the FGDs of females and hospital staff were the best sources of data for the undesirable/harmful attitudes and practices of males.

In addition, the most frequently stated practices in the FLIs were similar to those stated in the FGDs.

In the circumstance, therefore, it is difficult to establish an position that the females and hospital staff were biased against the community males. Indeed, these similarities between the FGD and FLI data may have positive implications for inter-partner harmony in the content of and response to information, education and communication programmes.

A general feeling among the FGD participants was that male attitude was unsatisfactory. This is aptly illustrated by a participant's perception that a man simply impregnates a woman ("does his own") and leaves her to face the hazards of pregnancy and delivery alone ("walks away"). The picture being painted is that men were uncaring, but this is not invariably the case.

Some of the beneficial attitudes and practices, such as providing money for maternal care, border on economic support. This is desirable, but where such care is not given, it may be difficult to determine whether it is a situation of true financial neglect or one of frank poverty. In this study, poverty may be a reason why a man may send his pregnant wife to live with her mother, thus avoiding the financial responsibility of care. Poverty is a well-known determinant of maternal mortality. ${ }^{11}$ Even then, this does not rule out cases of real neglect that is unconnected with poverty.

It is noteworthy that several undesirable attitudes and practices, such as battering, cannot be entirely blamed on poverty. Battering is global, except in some small societies where the practice is virtually absent. ${ }^{12,13}$ It results in physical and psychological injury. An added cause for concern is the permissive attitude of the women in this study towards the beating of a female on the grounds that some females are 'stubborn' or 'bad'. Equally worrisome is the third party involvement of a woman's mother and a boyfriend's family in battering females. A similar study among the Tiv in Nigeria shows that a man is justified to beat his wife or partner if she is disobedient, disrespectful, refuses sex or refuses to bear more children. ${ }^{14}$ These approvals of female battering illustrate cultural tolerance of a harmful practice.

A close look at the results shows that single and married female groups discussed the negative impact of suspicion in inter-partner relationships. The single females spoke about males withholding care for their pregnant single sexual partners on the grounds of uncertainty about her true intentions. Along a similar line of thought, the women talked about men sometimes preferring small family sizes against their wives' wishes, the reasons proffered for this point being a woman's

African Journal of Reproductive Health Vol. 11 No.1 April 2007 
uncertainty about her husband's true intentions, rather than her actual preference for more children. Thus, a woman's desire for more children may be her perception of her husband's wishes. On the other hand, a man's desire for more children may conflict with his wife's desire to use a family planning method, as shown in one of the accounts on battering. On the whole, it appears that one important factor contributing to conflicts on desirable family size, the use of family planning methods and the willingness to provide care is that of poor inter-partner communication. Interestingly, the women expressed a desire to communicate with their partners. Trends in the FGDs suggest that the discussants actually see inter-partner communication as a critical intervention point to contribute to their reproductive wellbeing. A related qualitative study in Mali also points to poor inter-partner communication on pregnancy and family planning as a challenge requiring intervention in order to control maternal and infant morbidity and mortality. ${ }^{15} \mathrm{~A}$ causal relationship between the complexes of events around inter-partner communication with respect to reproductive health may not always be unidirectional. For example, it is possible that disagreements on adequate family size and the fear of being beaten or divorced may impede interspousal communication on family planning; this relationship may also occur vice versa. Either way, inter-partner communication is an important link in correcting some male attitudes and in building harmony and consensus.

The assumption that all pregnancies and deliveries are normal is as dangerous as the belief that witchcraft and enemy influences are the causes of complications. Interestingly, these observations about male attitudes were made by the hospital staff group rather than women who, instead, raised objections to being blamed by men for illluck in the face of pregnancy complications. The fact that the superstitious beliefs were not exclusively held by men underscores the need to direct interventions at both males and females in addressing such cultural problems. Of course, both the superstitious and the jinx labelling are perpetuated by men and are stigmatising and harmful to the integrity of womanhood. Worse still, such ideas may give room for neglect, malice and maltreatment in the face of a treatable lifethreatening obstetric emergency. It is for these reasons that men require additional attention during interventions.

The wide range of attitudes and practices described and discussed pose challenges and opportunities for behaviour change interventions that take into consideration the multi-factorial nature of the identified gaps in the community. One approach to solving these problems is to develop and implement multi-sectoral initiatives that are initially government-led but ultimately community-driven.

The local government authorities in charge of health, information, women affairs, education, youths, etc., should, in collaboration with relevant nongovernmental organisations and higher levels of government, initiate continuous information, education and communication programmes that will improve on males' knowledge, attitude and practice regarding safe motherhood in the community. Such programmes should also build partnerships with existing traditional institutions to shift from harmful culture-based attitudes and practices to the healthful ones. This approach has been recommended in a previous Nigerian study on safe motherhood. ${ }^{16}$ Priority should be given to unfettered inter-partner communication and enhancement of the status of females, without appearing to confront cultural values. Formal education should be extended to all with emphasis on adult and female education. This will enable better communication and access to reproductive health information. It is also desirable to implement poverty alleviation programmes that can guarantee improved household income and enable healthful behaviour and access to health services in the community. 
The male attitude to safe motherhood has a bearing on the utilisation of reproductive health services. The systemic problems in the community district hospital would therefore confound a clear determination of the extent to which men may be seen as having negative attitudes to modern reproductive health services. It is remarkable that women in this study seem to share in their husbands' reservation about the hospital, going by the common opinion that the unstable and minimal services available are too expensive. However, the accounts of pregnancy against medical advice, prolonged labour at home, home delivery and over-aged fathering seem to suggest that some men resent modern medical facilities and medical advice. The maternal and child deaths associated with these events are disturbing instances of preventable deaths.

Institutional, infrastructural and service reforms in the local district hospital should be vigorously pursued by the state government and other stakeholders to correct the serious gaps. Maternal health services should be reinforced (laboratory and operating theatre made functional, etc) to meet the needs of emergency obstetric care. The services should be made more affordable, effective and efficient in order to encourage their utilisation. Emergency obstetric services should be readily available and free of direct charge. It is particularly important to ensure adequate staffing of the hospital on a continuous basis so as to ensure 24-hour-daily services.

Males could be specifically mobilised, as household decision makers, to support and enable their partners to use maternal health services where available, and to channel their resources to improve on existing ones when they are inadequate.

On the whole, it is hoped that male partners, in line with evolving global trends, would play better promotive roles in safe motherhood, ${ }^{17}$ especially in developing countries like Nigeria.

It can be seen from the foregoing that the data obtained from the FGDs, buttressed by the
FLIs and group interviews, provided important insights that could hardly have come from a quantitative survey method alone. Health researchers, especially those studying behaviour-related health problems, are therefore challenged to draw from the varied strengths of different qualitative research methods.

In this study, qualitative data were collected and used to uncover issues in male involvement in safe motherhood. Several methods were used, partly to capture their different advantages and to enable readers appreciate their uses. Unfortunately, this difference in methods may have created bias when comparing data outputs. Functional quantification procedures would also have been useful in assigning relative weights to the actual occurrence of harmful and beneficial practices, such as number of occurrences per couple over a given time. Although additional supportive data from other sources were collected, more female FGDs may have provided more data that could demonstrate more views on female perceptions about males. While these data were probably sufficient as illustrations and as a baseline with which to initiate interventions in this relatively small community, more detailed studies that make provision for a wider range and categories of socio-demographic characteristics (especially income, age, educational level and place) are required to enable a broader understanding of the subject in larger settings. That way, wider generalisations can be made.

\section{Acknowledgement}

The authors are grateful to Professors Bayo Parakoyi, Obehi Okojie and M. K. O. Padonu for their useful comments in putting this work together. We are also grateful to the people of Ekiadolor for their participation in the study.

African Journal of Reproductive Health Vol. 11 No.1 April 2007 


\section{REFERENCES}

1. United Nations Children's Fund (UNICEF). State of the World's Children: Girls, Education, and Development. http://www.unicef.org/sowc04/. New York: UNICEF. 2004.

2. Okojie C. Results from Survey Data and Focus Group Discussion 1993. In: Studies in Reproductive Health in Nigeria. FMOH/UNFPA. July 1998.

3. Helzner J. F. Men's Involvement in Family Planning. Reproductive Health Matters. May 1996; 7: 146-53.

4. Gharoro E.P., Igbafe A.A. Antenatal Care: Some Characteristics of the Booking Visit in a Major Teaching Hospital in the Developing World. Proceedings of the 5th International Congress of the Society of Gynaecology and Obstetrics of Nigeria. 25-28 November. 1998.

5. Palma-Sealza L., Costello M.P. and Echavez C. Male Involvement through Reproductive Health Awareness in Bukidnon Province, the Philippines: An Intervention Study. Population Council, Manila/Department of Health/USAID. June 1998; 46-7.

6. Shehu D., Ikeh A. T., Kuna M.J. Mobilising Transport for Obstetric Emergencies in NorthWestern Nigeria. Int. J. Gynaecol. Obstet. 1997; 59 (Suppl.2): 173-80.

7. Prevention of Maternal Mortality Network. PMM Results Conference: Abstracts. New York: Centre for Population and Family Health, Columbia University. November 1996.

8. Neema S. Conducting Successful Focus Groups and Analysis: Experience from a Pilot Study on Family Planning and Sexual Behaviour in the Era of HIV/AIDS and STDS. Afr J Reprod Health 1998; 2 (2): 175-82.

9. Shah M. K., Zambezi R., Simasuki M. Listening to Young Voices: Facilitating Participatory Appraisals on Reproductive Health with Adolescents. CARE International in Zambia. June 1999.

10. Olawoye J. E., Omololu F. O., Aderinto Y., Adeyefa I., Adeyemo D., Osotimehin B. Social Construction of Manhood in Nigeria: Implications for Male Responsibility in Reproductive Health. African Population Studies. January 2005; 19 (2): 1-20.

11. Harrison K.A. Maternal Mortality in Nigeria: The Real Issues. Afr J Reprod Health. 1997; 1(1): 7-13.

12. Counts D. A., Brown J., Campbell J. eds. Sanctions and Sanctuary: Cultural Perspectives on the Beating of Wives. Westview Press, Boulder, Colorado. 1992.

13. Levinson D. Violence in Cross Cultural Perspective. Newbury Park, California, Sage Publications. 1989.

14. Odimegwu C. O. Couple Formation and Domestic Violence among the Tiv of Benue State, Nigeria. UEPA/ UAPS, INED, ENSEA, IFORD. Abidjan. 16-21, July 2001.

15. Clemmons L., Coulibaly Y. ['We Don't Talk About It'] Qualitative Research on Knowledge Attitudes and Practices Concerning Pregnancy. Family Planning and Maternal Care in the Koila Sector. Final Report. Dioro, Mali, Africare, Project Survie de l'Efant-Dioro [PSED]. 1993 Nov. - Dec. x, 41p.

16. Okolocha C., Chiwuzie J., Braimoh S., Unuigbe J., Olumeko P. Sociocultural Factors in Maternal Morbidity and Mortality: A Study of a Semi-Urban Community in Southern Nigeria. I Epidemiol Community Health. 1998 May; 52 (5): 293-7.

17. World Health Organisation. Make Every Mother and Child Count. World Health Day 2005 Information Kit. W.H.O. April 72005.

18. National Population Commission. 1991 Population Census of Nigeria.

19. National Population Commission. Nigeria Demographic and Health Survey 2003. National Population Commission. Abuja, Nigeria. April 2004.

20. Zimbabwe National Family Planning Council. IEC Reference Manual for Health Programme Managers. Zimbabwe National Family Planning Council. Harare, Zimbabwe. 1994. 